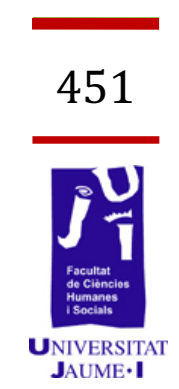

\title{
Estudi pilot sobre les diferències de la memòria en l'edat realitzat amb estudiants de psicopedagogia i de la Universitat per a Majors de I'UJI
}

Aida Sanahuja Ribés al106899@uji.es

Irene García Molina al106890@uji.es

Sara Romero Gonell al106893@uji.es

Verónica Sanz Ávila al106988@uji.es 
La memòria és una facultat dels organismes humans per recuperar informació prèviament emmagatzemada a partir de les dades de l'experiència. Aquesta capacitat de tenir records es veu possibilitada a partir de la sinapsi neuronal i la interconnexió entre diverses àrees cerebrals. En general, els models estructurals (Atkinson i Shifgrin, 1968), ens informen de tres tipus de memòria com: la memòria sensorial, la de curt termini i la de llarg termini. Però ben bé, estudis recents informen que la memòria és un procés unitari.

L'objectiu d'aquest estudi és analitzar els factors que afecten a la memòria al llarg del desenvolupament. Més en concret, com la memòria pot sofrir modificacions en l'edat. Les dades que analitzem es centren en dos grups de població: joves entre 20 i 30 anys (estudiants de psicopedagogia), i majors de 55 a 65 anys (estudiants de la Universitat per a majors), tots estudiants de la Universitat Jaume I, de Castelló.

Hem utilitzat la prova estandarditzada "Memoria visual de rostros", en la qual es presenta al subjecte una sèrie de rostres amb dades referides a cada persona (nom, cognoms, professió i ciutat) i es mesura la quantitat d'estímuls que recorden.

Els resultats evidencien una clara diferència entre els grups participants. Constatant d'aquesta forma, que els joves han aconseguit una puntuació més prominent que la població de majors.

Paraules clau: memòria, edat, envelliment, MVR.

\section{Introducció}

La memòria és una facultat dels organismes humans per recuperar informació prèviament emmagatzemada a partir de les dades de l'experiència. Aquesta capacitat de tenir records es veu possibilitada a partir de la sinapsi neuronal i la interconnexió entre diverses àrees cerebrals. Trobem tres tipus de memòria com: la memòria sensorial, la de curt termini i la de llarg termini.

L'estudi de la memòria a interessat al llarg de la història. Ja en l'antiga Grècia, segons es referència en López (1999), els individus s'entrenaven específicament en memòria, una de les divisions de la retòrica, i les persones capaces de recitar llargs passatges de les obres clàssiques eren admirades perquè una bona memòria es considerava un símbol de perfecció moral. Tan gran era la importància d'aquesta habilitat en la cultura hel-lènica, que Mnemòsine, musa de la memòria, del nom de la qual deriven els mots mnemònic (relacionat amb la memòria) i amnèsia (pèrdua de la memòria), no sols era la mare de les altres muses, sinó que era també una de els esposes de Zeus.

D'acord amb la importància que li donaven els grecs, la naturalesa de la memòria va ser objecte de moltes especulacions filosòfiques. Com per exemple Sòcrates (470-399 a.C.) considerava la memòria com una tabula 
rasa, és a dir, en la memòria al nàixer no hi ha cap "inscripció" i les nostres experiències són les que deixen marcades unes impressions. A més Plató (429-348 a.C.), considerava que aprendre és recordar (doctrina de l'anamnesi), ja que per comunicar un coneixement es parteix de la memòria; per captar una nova dada és necessari connectar-la amb les anteriors i l'experiència passada és imprescindible per adquirir-ne de nova.

La idea que la memòria es guarda en alguna part del cervell té el seu origen en els estudis de Galè (130-200), el qual creia que residia als ventricles cerebrals. Actualment sabem que aquestes cavitats són plenes de líquid cefaloraquidi i no tenien la funció que se li atribuïa.

En el Renaixement, Andreas Vesal (1514-1564), va proposar que el cerebel era el lloc on es conservava la memòria (actualment sabem que el cerebel controla l'exactitud dels nostres moviments). Durant aquesta època altres autors van aportar idees semblants. No va ser, fins finals del s. XVII, quan el metge Thomas Willis va afirmar que era el cervell on es regia aquesta funció. Ja a finals del segle XIX quan va arribar l'estudi científic de la memòria: I'any 1885, Ebbinghaus va publicar una monografia titulada Über das Gedächtnis: Untersuchungen zur experimentellen Psychologie (Sobre la memòria: una contribució a la psicologia experimental), un treball que constituiia la primer anàlisi experimental de la memòria humana. L'objectiu de la investigació era esbrinar quanta informació nova podia conservar un individu i com de ràpidament l'oblidava. A partir d'Ebbinghaus fins l'actualitat totes les investigacions van seguir aquesta línea, és a dir, la línea de la investigació científica.

A partir de finals del s. XIX i principis del s. XX, el coneixement de la memòria ha sofert destacats canvis d'acord a la investigació $i$ els instruments tècnics emprats pel seu estudi. Així, tenint en compte que la memòria és una capacitat dels organismes vius, i principalment dels humans, que ens permet adaptar-nos a l'entorn, consisteix, en línies generals adquirir, retenir i utilitzar informació de diverses experiències viscudes, relatades, etc. (Tulving, 1972). Aquesta presenta tres fases o processos complexos i successius: la codificació de la informació, el seu emmagatzemament, la retenció en el temps i la recuperació en un moment posterior $\mathrm{i}$ en el moment adequat. Hem de recalcar que és a partir de l'emmagatzemament, quan es pot produir un oblit progressiu (si no es realitzen distintes activitats per consolidar i mantenir la informació) tot i que l'oblit absolut mai es dóna (a no ser que s'hagi produït alguna malaltia).

S'ha demostrat que, en concret, les dimensions de codificació i la recuperació guarden paral-lelismes neurològics i fisiològics; ambdues es relacionen amb zones de creació de nous aprenentatges (hipocamp). En la codificació cal elaborar la informació, crear associacions, organitzar els ítems de record i integrar-los en les estructures prèvies de memòria presents en l'individu. En la recuperació, els processos implicats són: recerca de pistes rellevants, elaboració sobre aquestes pistes i el control del record. Realment cal afegir que hi ha una gran diversitat de zones en les que es poden establir les associacions de record, fet que reafirma la complexitat del procés d'aprenentatge i memorització dels éssers humans. 
Així mateix, els autors (Atkinson i Shiffrin, 1968) parlen bàsicament de l'existència de tres models explicatius de la memòria:

1) Memòria sensorial: Registra la informació que prové de l'ambient extern (imatges, sons, olors, sabors i el tacte de les coses) durant un temps molt breu, però el suficient per a que eixa informació sigui transmesa a la MCT (Memòria a Curt Termini) (Alonso, Alonso i Balmori, 2002). Segons l'experiment d'Sperling, els subjectes analitzats en aquest no retenien 30 4 lletres -com inicialment s'havia suposat- sinó que retenien com una imatge completa totes les lletres que havien vist. A partir d'aquest experiment, s'hi va deduir que la duració de la Memòria Sensorial no sobrepassava un quart de segon (250 milisegons).

2) Memòria a curt termini: La informació emmagatzemada en la Memòria Sensorial es transmet en part a la Memòria a Curt Termini, abans de passar a la Memòria a Llarg Termini. La funció de la MCT és organitzar i analitzar la informació (reconèixer cares, recordar nombres, contestar en un examen...) i interpreta les nostres experiències (Alonso, Alonso i Balmori, 2002).

D'una sèrie d'elements, aquesta memòria recorda millor els primers $\mathrm{i}$ els últims. També recorda millor els elements separats en petites unitats que en una llista llarga (per aquest motiu s'acostumen a donar els telèfons separats en grups de dos i tres xifres). La memòria a curt termini és sobretot ecoica i és un magatzem separat de la memòria a llarg termini, que sembla ubicar-se en el còrtex prefrontal. El primer investigador en postular aquesta diferenciació va ser William James (1890), però ell l'anomenava memòria primària (la de curt termini). El pas de la memòria de curt a llarg termini es pot veure afectat per l'emoció del moment (els records emocionalment intensos són més fàcils de passar a la memòria de llarg termini) i pel lligam de la nova informació amb l'antiga. Així, com proposa l'aprenentatge significatiu, és més senzill recordar una dada si aquesta es connecta amb el corpus general de coneixement del cervell, ja que llavors pren sentit i activa les connexions mentals. També és més probable la retenció si els estímuls visuals i acústics es donen alhora, perquè sembla que aquesta memòria treballa amb dos subsistemes diferents. Aquest fet explica que es puguin fer dues tasques alhora que no requereixin usar el mateix subsistema (es pot escoltar una notícia i fixar-se en les imatges) però en canvi si impliquen compartir informació, el temps de resposta augmenta o l'èxit de la tasca és pitjor (les distraccions impedeixen seguir escoltant amb atenció, per exemple).

3) Memòria a llarg termini: La MLT, conté els nostres coneixements del món físic, de la realitat social i cultural, els nostres records autobiogràfics, així com el llenguatge i els significats dels conceptes. A més, enllaça el passat en el present (Alonso, Alonso i Balmori, 2002). La MLT té capacitat il-limitada i no és una entitat unitària, sinó que està constituïda per diferents sistemes de memòria que emmagatzemen diferents tipus de coneixement.

Segons el neuropsicòleg Lary Squire (citat en Alonso, Alonso i Balmori, 2002) existeixen dos sistemes de memòria: procedimental (coneixement 
automàtic) i el declaratiu (coneixement conscient). La memòria procedimental és la que fa referència a les tècniques, com per exemple escriure. La tècnica s'aprèn per mimetisme o repetició, de forma gradual. En els primers estadis, la persona avança més ràpidament, mentre que després el progrés és menor però la fixació és més segura. Si la tècnica s'aprèn correctament, no s'oblidarà mai.La memòria declarativa és més fàcilment comunicable a altres persones, perquè fa referència a fets $i$ conceptes i per tant està totalment estructurada pel llenguatge.

Segons el psicòleg canadenc Endel Tulving (citat en Alonso, Alonso i Balmori, 2002) es reconeix que el coneixement emmagatzemat en la memòria a llarg termini no és tota igual, i hi distingeix dos tipus: l'episòdica i la semàntica. La memòria episòdica fa referència a les experiències viscudes en un temps i un espai concret, mentre que la semàntica s'ocupa d'abstraccions. Mútuament s'influencien, ja que veure un exemple particular pot fer variar la concepció general d'un fenomen i el concepte sol formar-se a base de diferents exposicions a l'estímul.

Mitjançant el model estructural de la memòria d'Atkinson i Shiffrin (figura 1), podem veure gràficament l'explicació i comprovar cóm les tres formen part del procés de la memòria, i es poden interrelacionar:

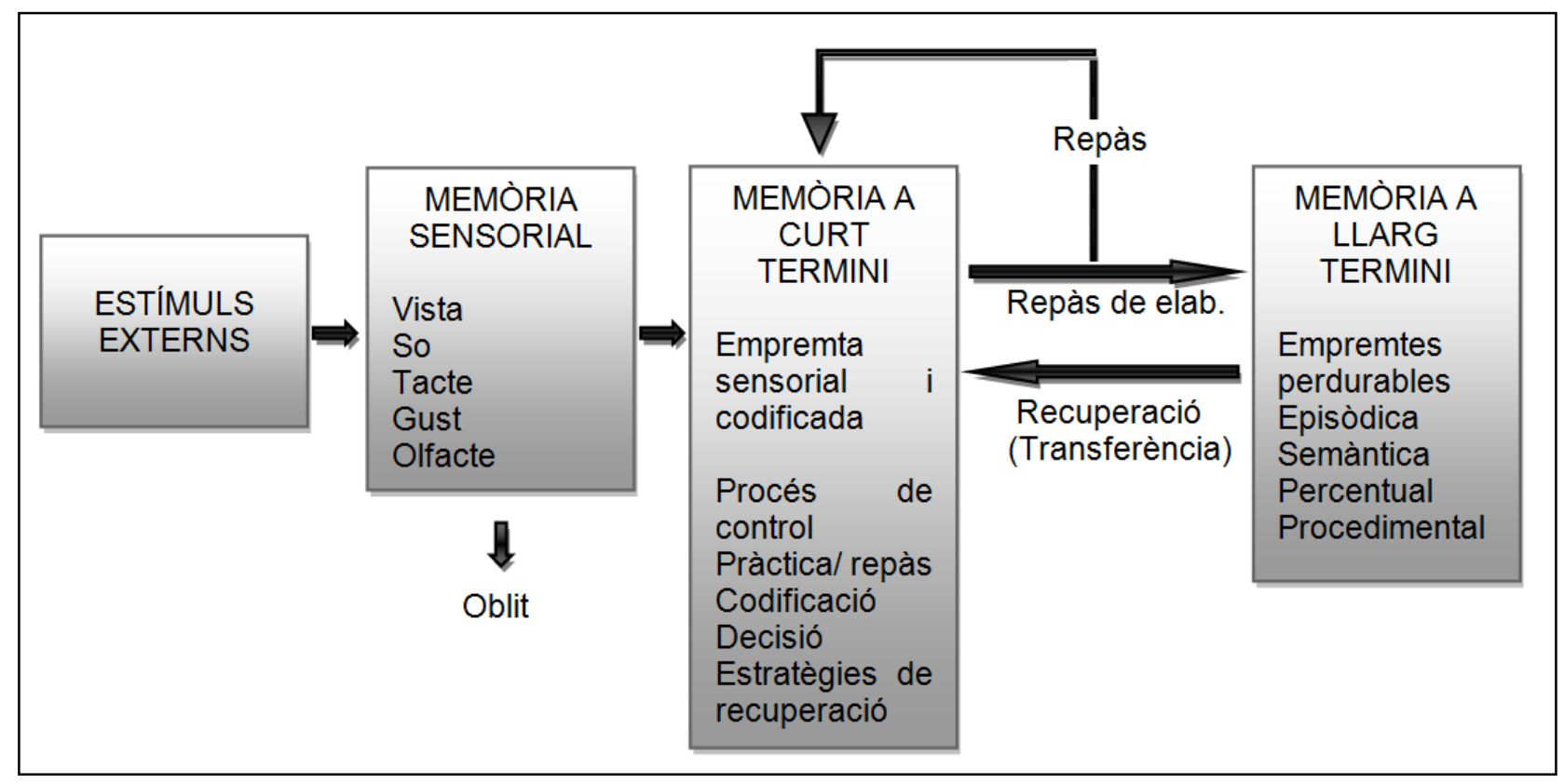

Figura 1. Model estructural de la memòria en tres etapes, segons Atkinson i Shiffrin (1968).

Després d'aquesta breu contextualització sobre la memòria, ens anem a centrar en la relació que s'estableix entre dues variables: l'edat i la memòria. L'objectiu de la nostra investigació és comprovar si l'edat és un factor que influeix directament a la capacitat de memòria. En concret, tractarem de comprovar la següent hipòtesis: a mesura que augmenta l'edat, menys memòria. És per això, que hem utilitzat la prova estandarditzada "Memoria Visual de Rostros" (MVR). En aquesta prova es 
presenta al subjecte una sèrie de rostres amb altres dades referides a cada persona (nom, cognom, professió i ciutat) i es mesura la quantitat d'estímuls que recorden.

El nostre treball no es centra en una mostra de població que presenta cap tipus de patologia relacionada amb la memòria, sinó que és una població amb un procés d'envelliment saludable. No obstant això, cal recordar que existeixen patologies en la memòria relacionades amb el procés d'envelliment, com ara:

- Amnèsies: trastorn de memòria associat a l'envelliment (AMAE), alzheimer, amnèsia global transitòria (AGT) y Síndrome de Korsakoff.

\section{Memòria i envelliment}

Partim del fet que l'envelliment pot afectar la memòria, i efectivament, així és. Segons García Meilan (2009) l'envelliment afecta canviant la manera com el cervell emmagatzema la informació i fent més difícil recordar la informació ja emmagatzemada. Això s'explica pel propi procés d'envelliment. L'envelliment consisteix en una pèrdua neuronal progressiva, i aquesta pèrdua de cèl-lules cerebrals, unit a la fabricació de menys substàncies químiques necessàries pel seu funcionament, tenen com a conseqüència directa la pèrdua de capacitat de noves connexions (entenem, nous aprenentatges,...) i la pèrdua d'associacions de les ja establertes o informació, afectant de la manera ja anunciada a la memòria. Així doncs, podem preveure cóm les variables edat i memòria correlacionen entre sí d'una manera determinada. La representació gràfica pren forma de " $U$ " invertida: unes primeres etapes de creixement i millora seguides de una fase més o menys prolongada de estabilitat per a, en les ultimes dècades de la vida, acabar amb un període de declivi i pèrdua (Pinazo i Sánchez, 2005).

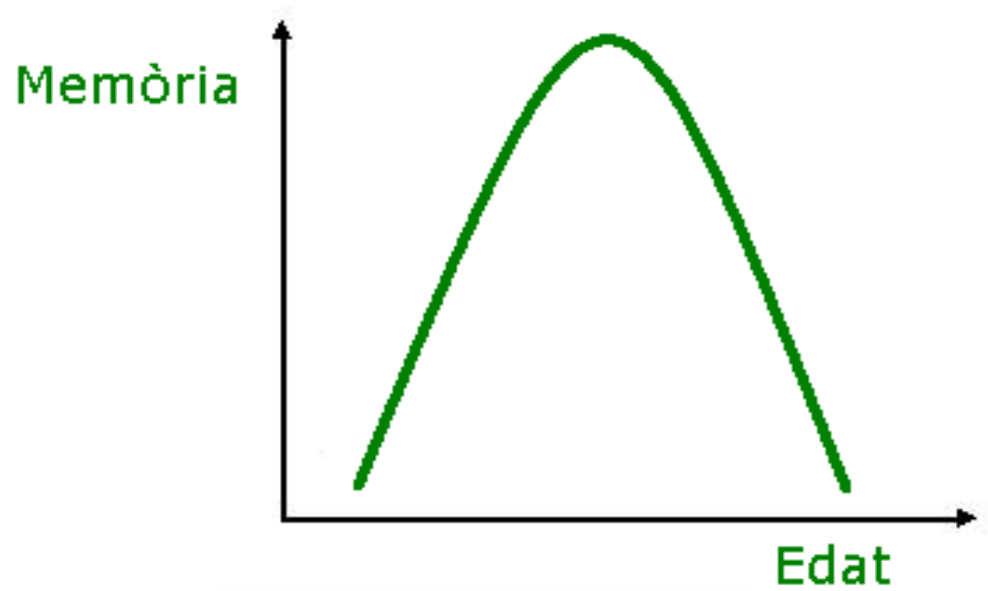

Figura 2. Declivi de la memòria: forma de " $U$ " invertida. 


\section{Objetiu}

En relació a allò explicat en els paràgrafs anteriors, l'objectiu de la nostra investigació és comprovar si l'edat és un factor que influeix directament a la capacitat de memòria.

En concret, tractarem de comprovar la següent hipòtesis: a mesura que augmenta l'edat, major pèrdua de memòria.

\section{Material i mètode}

Per comprovar la hipòtesi anterior passarem a definir els participants del nostre estudi, l'instrument i el procediment utilitzat per dur a terme el següent treball.

\section{Participants}

Pel que fa a la mostra de població, cal destacar que els subjectes han sigut elegits dintre del context universitari, diferenciant dos grups: joves i majors. De fet, la selecció de la mostra dels majors s'ha realitzat també dintre de la població universitària perquè, com indiquen els estudis consultats, suposem un nivell d'activitat neuronal i d'activitat a nivell de processos cognitius més equiparable amb la mostra jove. Així doncs, mitjançant aquest criteri estem controlant la influència de possibles variables estranyes, com ara el nivell cultural. La mostra es dividís en dos grups:

Grup A: integrat per 10 joves universitaris estudiants de $1 \mathrm{r}$ de psicopedagogia en edats compreses entre els $20 \mathrm{i}$ els 30 anys. Dels quals 4 eren xics i 6 eren xiques.

Grup B: integrat per 10 persones majors de 55 a 65 anys que assisteixen a les classes de la Universitat per Majors de I'UJI, en l'especialitat d'humanitats. Dels quals 2 eren homes i 8 eren dones.

Instrument

L'instrument que vam utilitzar per a realitzar la investigació va ser el test de "Memoria Visual de Rostros". La fitxa tècnica de la prova es la següent:

Taula 1. Fitxa tècnica.

\begin{tabular}{|l|}
\hline \multicolumn{1}{|c|}{ Fitxa tècnica. } \\
\hline Nom: MVR, “Memoria Visual de Rostros". \\
\hline Autor: Nicolas Seisdedos. \\
\hline Procedència: Dpto I+D de TEA. Edicions, S.A., Madrid. \\
\hline Aplicació: individual i col·lectiva, adolescents i adults. \\
\hline Durada: 4 minuts la presentació d'estímul i 4 minuts la prova efectiva. \\
\hline $\begin{array}{l}\text { Significació: capacitat per recordar representacions fisonòmiques de persones i dades } \\
\text { associades a elles. }\end{array}$ \\
\hline $\begin{array}{l}\text { Tipificació: Barems en centils i puntuacions típiques en una mostra de la població } \\
\text { general d'adults, independentment per cada sexe. }\end{array}$ \\
\hline
\end{tabular}


La intencionalitat de la prova es apreciar la memòria per a recordar rostres de persones, associats a petits detalls de la seua representació pictòrica i a les seues dades d'identificació (nom, cognoms, professió i lloc de treball). Per tant, el que es demana és atendre a diversos continguts específics dels estímuls presentats i fer una associació entre ells per a reforçar la memorització.

Es una prova realitzada per a mesurar la memòria a mitja termini ja que s'introdueix mascares o elements distractors amb la finalitat d'augmentar el temps entre l'exposició als estímuls i la posterior recuperació dels continguts. En el nostre cas, com a element distractor vam utilitzar el càlcul mental d'una operació d'uns 7 elements numèrics. Vam anotar a la pissarra la següent operació:

$$
4+2+3-6+9-1+8=
$$

\section{Procediment}

L'aplicació de la prova es va dur a terme en diversos moments, partint de la disponibilitat dels subjectes. D'una banda, vam passar la prova als subjectes de la universitat per a majors en el mateix lloc i en el mateix moment, aprofitant una aula lliure de la facultat. Es destacable que els subjectes es van mostrar col-laboratius en la realització de la prova, tot $\mathrm{i}$ que, en ocasions, alguns van parèixer desconfiats ja que no volien indicar la seua edat. D'altra banda, vam passar la prova als subjectes de la mostra de joves de forma més dispersa donat que va ser impossible reunir a tots a la mateixa hora.

\section{Resultats}

A continuació, presentem en la taula 2 les dades obtingudes pel que fa a la mostra de població jove on recollim la puntuació directa, centil i la desviació típica (S). Posteriorment, presentem la gràfica 1 on es pot observar la puntuació centil obtinguda per comparar més clarament els resultats entre els joves. 
Taula 2. Mostra jove de 20 a 30 anys.

\begin{tabular}{|c|c|c|c|}
\hline Sexe & P. directa & P. Centil & $S^{1}$ \\
\hline Dona & 12 & 60 & 55 \\
\hline Dona & 16 & 95 & 83 \\
\hline
\end{tabular}

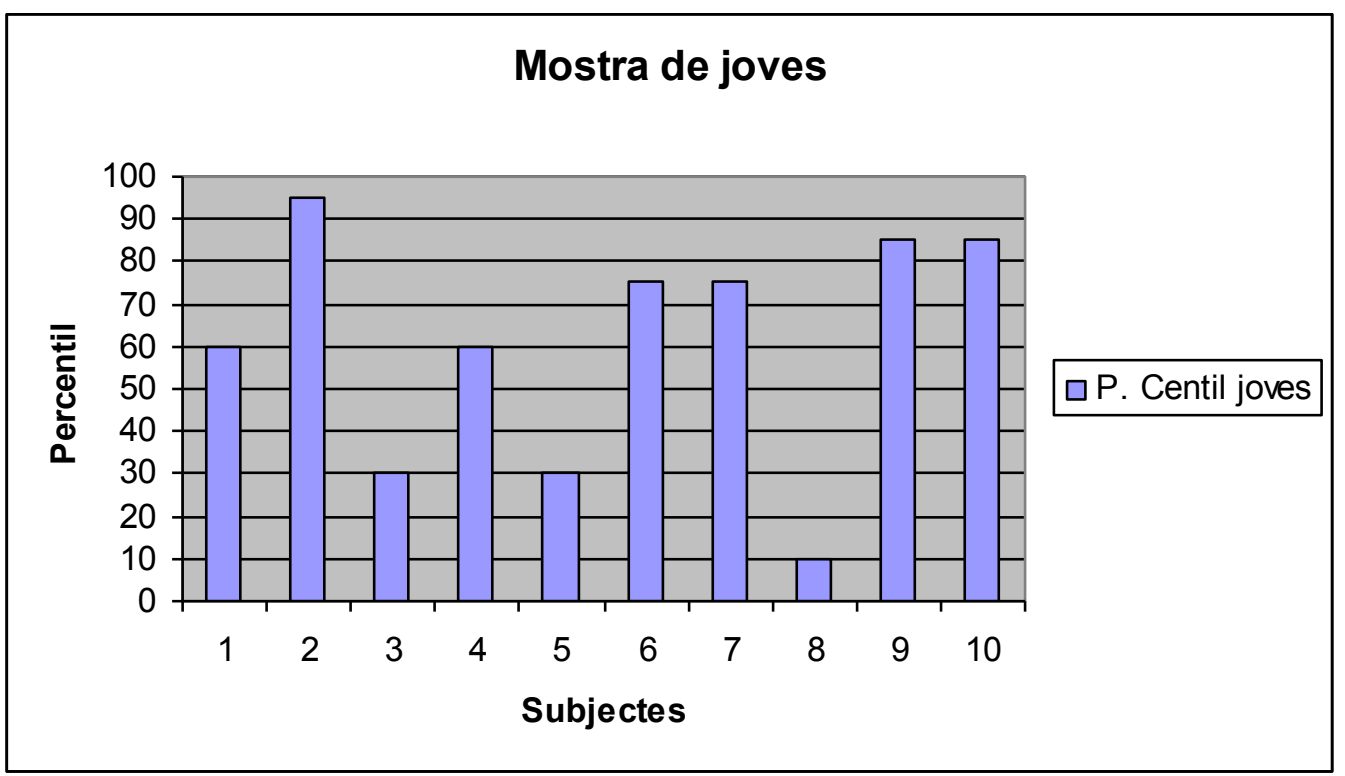

Gràfica 1. Mostra de joves.

Seguidament, en la taula 3 presentem les dades obtingudes pel que fa a la mostra de població pertanyent a la universitat per a majors on recollim la puntuació directa, centil i la desviació típica (S). Posteriorment, presentem la gràfica 2 on es pot observar la puntuació centil obtinguda per comparar més clarament els resultats entre els subjectes de la universitat per a majors.

\footnotetext{
${ }^{1}$ S'ha agafat com a referència les puntuacions qualitatives S (Mitja 50, DT 20).
}

Agraïments a Amparo Carpi Ballester, professora del Departament de Psicologia Bàsica, Clínica i 459 Psicobiologia de la Universitat Jaume I 
Taula 3. Mostra majors de 55 a 65 anys.

\begin{tabular}{|c|c|c|c|}
\hline Sexe & P. directa & P. Centil & $\mathbf{s}^{2}$ \\
\hline Dona & 5 & 5 & 17 \\
\hline Dona & 14.67 & 8 & 67 \\
\hline Dona & 4.67 & 4 & 12 \\
\hline Dona & 9.4 & 30 & 40 \\
\hline Dona & 3 & 2 & 9 \\
\hline Dona & 12 & 60 & 55 \\
\hline Dona & 11 & 45 & 48 \\
\hline Dona & 9 & 30 & 3 \\
\hline Home & 1.7 & 1 & 3 \\
\hline Home & 0.7 & 1 & \\
\hline
\end{tabular}
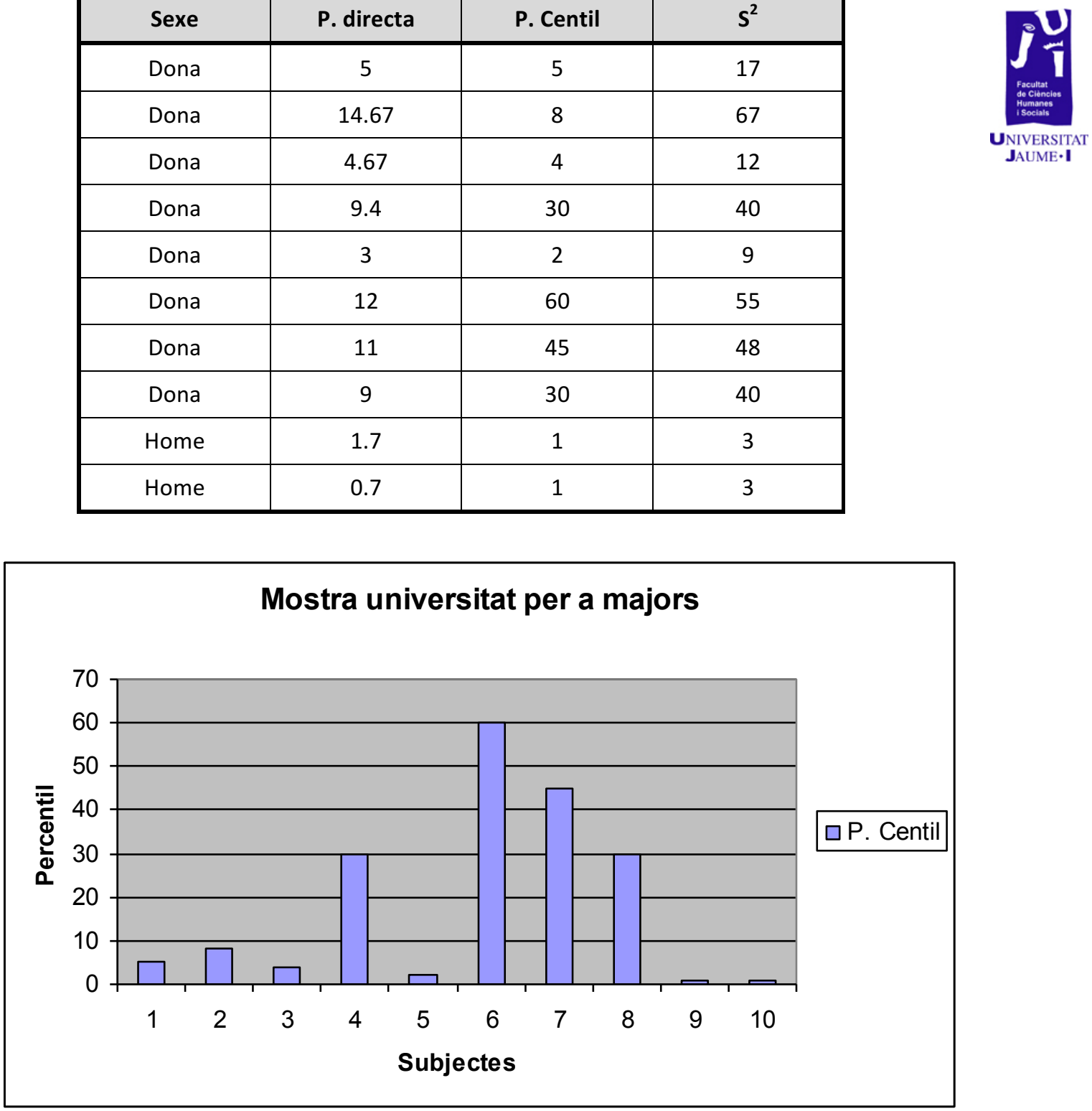

Gràfica 2. Mostra universitat per a majores.

La puntuació mitjana en la població de joves ha segut de 61.04. Mentre que, la puntuació mitjana en la població de la universitat per a majors ha segut de 11.18. Seguidament en la gràfica 3 podem veure la comparació entre les dos puntuacions.

\footnotetext{
${ }^{2}$ S'ha agafat com a referència les puntuacions qualitatives S (Mitja 50, DT 20).
} 


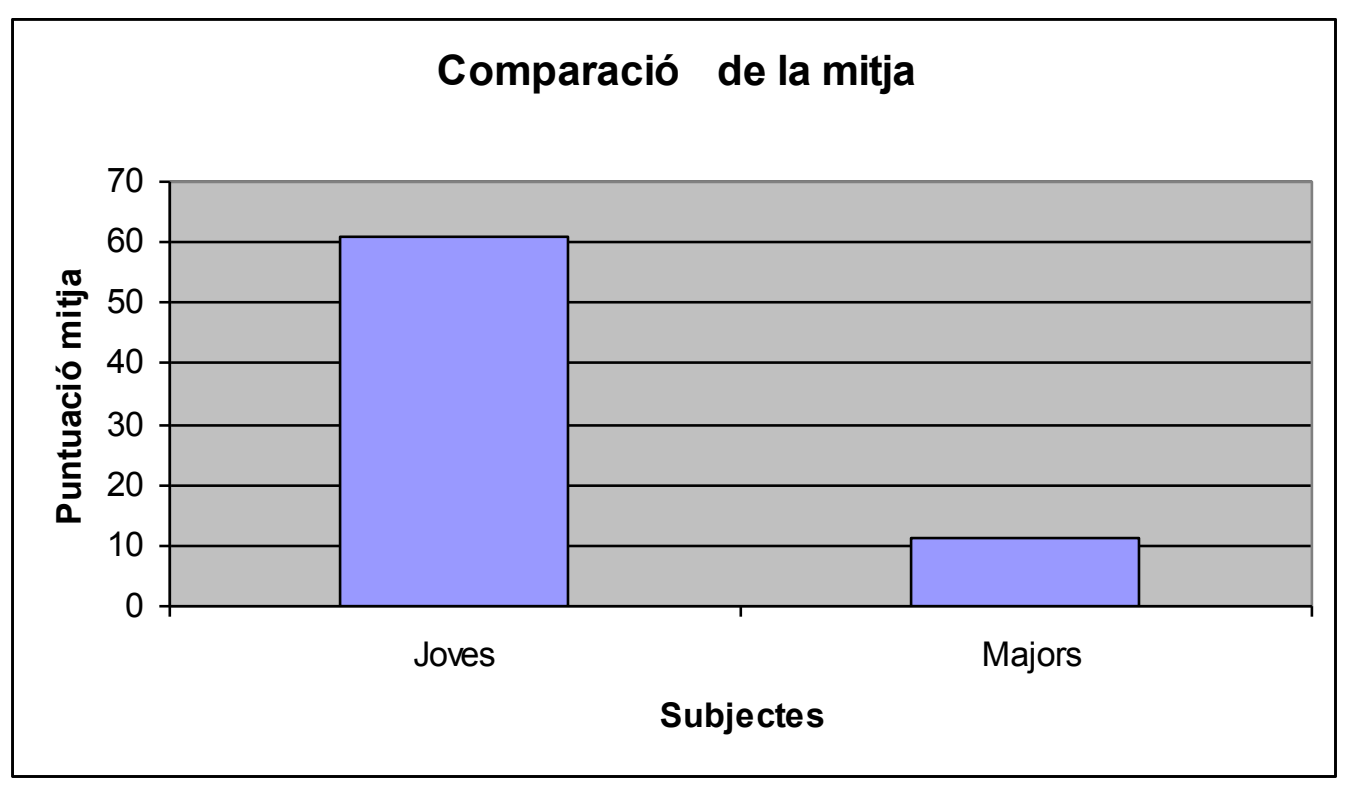

Gràfica 3. Comparació de la mitja entre joves i majors.

Tot seguit, passarem a analitzar la correlació. Els coeficients de correlació són estadístics que ens proporciones informació numèrica en referència al grau de relació existent entre dos variables, en aquest cas, l'edat i la memòria. El fet que hi hagi correlació entre dos variables, no vol dir que hi haja una relació de causalitat entre dites variables. Únicament ens estan indicant que hi ha una covariació, una variació conjunta o simultània entre variables, però no necessariament que una variable sigui causa de l'altra.

La correlació existent entre les variables edat i puntuació centil és de $.531^{* *}$, per tant les dos variables correlacionen significativament de forma negativa. La correlació es significativa al nivell 0.01 (bilateral). El fet que correlacionen de forma negativa indica que quan augmenta la variable edat disminueix la puntuació en la prova de memòria. En la gràfica 4 ho podem veure representat. 


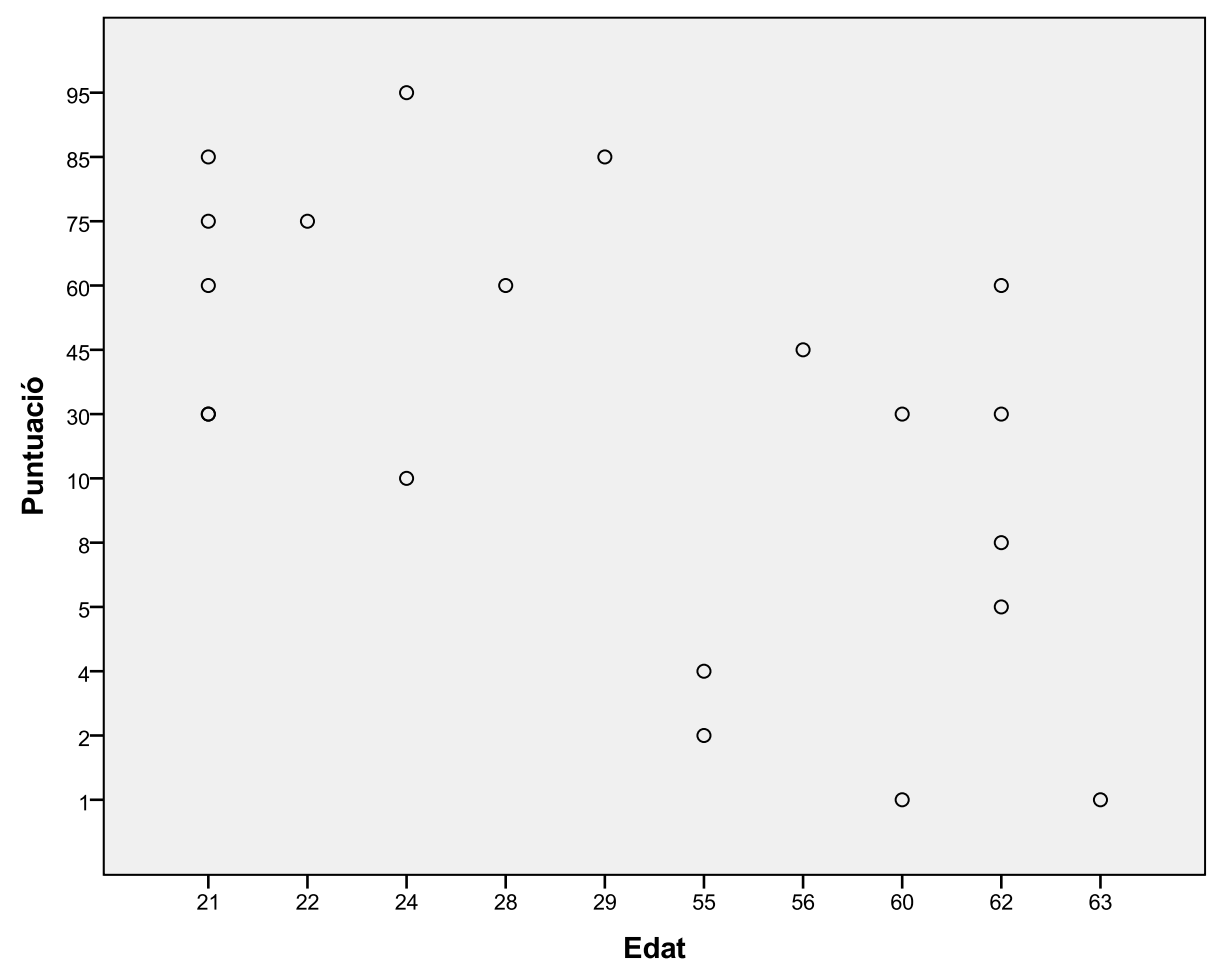

Gràfica 4. Correlació negativa entre memòria i edat.

\section{Discussió I conclusions}

Quant a l'objectiu de la nostra investigació (comprovar si l'edat és un factor que influeix directament a la capacitat de memòria) hem pogut veure que l'edat si que influeix en la capacitat memorística dels subjectes, vist que trobem diferències considerables entres ambdós grups de població.

Després d'analitzar les dades obtingudes, i tenint en compte el número reduït de la mostra de població, podem dir que la nostra hipòtesi (a mesura que augmenta l'edat, disminueix la memòria) es acceptada, ja que observem que les puntuacions mitjanes són més altes en la mostra de joves que en la mostra de la universitat per a majors.

\section{Limitacions de l'estudi}

La nostra hipòtesi no ha segut refusada, però pensem que la mostra de població ha sigut molt reduïda per poder generalitzar resultats ja que es tracta d'un estudi pilot per a una possible futura investigació amb una mostra més amplia. A més, encara que la prova pot ser col-lectiva, pensem que la millor forma d'administrar-la, seria per petits grups; ja que, així, $\mathrm{s}^{\prime}$ eviten possibles distraccions. A més, el fet de que totes dues mostres siguin universitàries, ha afectat a les respostes, sobretot en el grup de majors, ja que es suposa que puntuarien millor. Açò es pot atribuir a que el seu nivell cognitiu pot ser superior a majors de la seva edat que no cursen ningun estudi universitari. 


\section{Futures línies d'investigació}

Pensem que aquesta investigació podria tindre diverses vies per tal de continuar-la:

- Primerament, tal com ja hem citat, seria convenient fer un estudi amb una mostra de població més àmplia.

- Caldria destacar que seria interessant poder aplicar algun programa (estratègies memorístiques) per a treballar la memòria en ambdós grups, i veure així si els resultats després d'aquesta intervenció, s'han modificat, i per tant, si es pot millorar la puntuació en les proves de memòria.

- També seria interessant poder ampliar la investigació a més etapes de la vida de l'ésser humà, per exemple poder comparar l'evolució de la memòria des de la infantesa fins la tercera edat: infantesa, adolescència, adults, tercera edat.

- Un altra via d'investigació, seria descobrir el nivell d'influència de les emocions i dels processos motivacionals en la memòria.

- Es podria realitzar un estudi similar, però amb grups de mostra no universitària; és a dir, joves i majors sense estudis universitaris.

Així doncs, podem afirmar que tant en l'envelliment normal com en el patològic, la disfunció amnèsica és una alteració molt comú. Sens dubte, aquest fet afecta la qualitat de vida i a la capacitat de realitzar nous aprenentatges, així com al record d'informació valuosa. El deteriorament de la memòria associat amb l'edat és un fenomen normal en les persones d'edat més avançada, més que una etapa inicial d'una demència o altra malaltia. És important la detecció precoç dels trastorns de memòria per a poder prevenir i detectar possibles patologies senils.

\section{Bibliografia}

Alonso, J.I., Alonso, A. I BALmorI, A. (2002): <<La Memoria Humana >>, en Alonso, J.I., Alonso, A. I Balmori, A. (eds.): Psicologia (pp. 121-138). Mc Graw Hill, Madrid.

AtKInSON, R.C. \& SHIFFRIN, R.M. (1968): <<Human memory: A proposed system and its control processes $\gg$, in SPENCE, K.W.; SPENCE, J.T. (eds.): The psychology of learning and motivation (pp. 89-195). Academic Press, New York.

EBBinghaUs, H. (1885): Memory: A contribution to experimental psychology. Dover, New York.

García Meilan, J.J. (2009): <<Procesos de memoria en el proceso de envejecimiento saludable >>, en Guerrero, C., Gómez, C., CARPI, A., PALMERo F.(Eds.): Envejecimiento saludable y alteraciones. Generalitat Valenciana, Valencia.

James, W. (1989): Principios de psicología. Fondo de Cultura Económica, México. 
LóPEZ, J.C. (1999): El taller de la memòria. Edicions Bromera, Valencia.

PINAZO S. i SÁNCHEZ, M. (2005): Gerontología. Actualización, innovación y propuestas. Pearson Prentice Hall, Madrid.

SeISDEdos, N. (2002): Memoria Visual de Rostros (MVR). TEA Ediciones, Madrid.

TULVING, E. (1972): <<Episodic and semantic memory >>, in TULVING, E.; Donaldson, W. (Eds.): Organization of Memory (pp. 381-402). Academic Press, New York.

\section{Webgrafia}

La Memoria Sensorial. Proyecto de Innovación Docente. Aula Virtual de Psicología. Recuperado el 16 de diciembre de 2014, de http://www.ugr.es/ aula_psi/LA_MEMORIA_SENSORIAL.htm 